"Photocleavage of peptides and oligodeoxynucleotides carrying 2-nitrobenzyl groups". Ramos, R., Manning, B., Aviñó, A., Gargallo, R., Eritja, R. Helv. Chim. Acta, 92(4), 613-622 (2009).

doi: 10.1002/hlca.200800361

\title{
Photocleavage of Peptides and Oligodeoxynucleotides Carrying 2-Nitrobenzyl
}

\section{Groups.}

by Roger $\operatorname{Ramos}^{\mathrm{a}}$ ), Brendan Manning ${ }^{\mathrm{a}}$ ), Anna Aviñó ${ }^{\mathrm{a}}$ ), Raimundo Gargallo ${ }^{\mathrm{b}}$ ), and Ramon Eritja*, a).

$\left.{ }^{a}\right)$ Institute for Research in Biomedicine, IQAC-CSIC, CIBER-BBN Networking Centre on Bioengineering, Biomaterials and Nanomedicine, Edifici Helix, Baldiri Reixac 15, E-08028 Barcelona, Spain. (phone: +34 934039942; fax: +34 932045904; e-mail: recgma@cid.csic.es)

b) Department of Analytical Chemistry, University of Barcelona. Diagonal 647, E08028 Barcelona, Spain. 


\section{ABSTRACT}

Peptides and oligodeoxynucleotides containing photolabile 2-nitrobenzyl groups midsequence were prepared. Photocleavage of aqueous solutions of these compounds neared completion within 30 minutes to a few hours depending on the photolabile group used. A photolabile group was introduced in the loop of an intramolecular oligodeoxynucleotide hairpin. Melting curves of the hairpin with and without the complementary oligodeoxynucleotide showed a preference for intramolecular hairpin form, but an intermolecular duplex was observed after photolysis. These results open the possibility of using photolabile DNA hairpins for the fabrication of patterned surfaces.

Introduction.- Photolysis has been used extensively in organic chemistry and biochemistry. Several molecular groups are light sensitive and this property has been exploited to mask groups that are to be liberated at a particular time. 2-Nitrobenzyl groups are some of the most widely studied photolabile groups [1-2]. In the photolysis of 2-nitrobenzyl derivatives the nitro group is reduced to nitroso and the benzyl group is oxidised to carbonyl (scheme 1) [3-4]. Several derivatives of the 2-nitrobenzyl group have been used for the protection of amines, alcohols, carboxylic acids, imidazoles, phenols and phosphates [2, 5]. In some cases, low yields attributable to the reaction of the nitroso aldehyde with the amino groups have been reported [5]. The introduction of a methyl group in the benzylic position accelerates photolysis and minimizes secondary 
reactions, due to the formation of a methyl ketone that is less reactive than the aldehyde group [2, 5]. The 2-nitrobenzyl group has also been used as a photolabile link between peptide and the solid support in solid-phase synthesis [6-8]. The photolytic cleavage of the peptide supports allows the isolation of protected peptide segments for use in the synthesis of longer peptides [7, 9]. Moreover, photolabile groups are also used to analyze drug-protein interactions. In this case, masked or caged drug derivatives are synthesized and delivered to cells. Fast photoremoval of the masking groups allows the study of the in vivo behaviour of the drug [10]. Finally, photolabile groups are used for the protection of the 5'-end of nucleoside derivatives in the preparation of DNA chips. This technique allows the parallel synthesis in a single chip of thousands of 20-30mer fragments corresponding to a complete chromosome [11].

Here we explore the synthesis and photolysis of synthetic biomolecules (peptides and oligodeoxynucleotides) carrying a photolabile link in the middle of their sequence. The ultimate aim of this work is to link these photolabile molecules onto surfaces to obtain functionalized surfaces. Photolithography of these surfaces will result in the cleavage of the biomolecules in the illuminated area while in the masked area the biomolecules will remain intact. Utilising the self-assembling properties of these photolabile biomolecules will enable selective binding of various molecules to the cleaved or uncleaved biomolecules in the photolyzed and unphotolyzed areas respectively.

Results and Discussion.- 1. Synthesis of photolabile linkers. First an amino acid derivative carrying 2-nitrobenzyl was prepared (scheme 2). We selected a derivative of 4-aminomethyl-2-nitrobenzoic acid described elsewhere [8, 12, 13]. The synthesis of this compound was done according the bibliography $[12,13]$ with small changes. First 
the amino group of 4-aminomethylbenzoic acid (1) was protected by the acid stable trifluoroacetyl (TFA) group using ethyl trifluoroacetate (scheme 2). Nitration of the resulting compound produced excellent yields of the TFA derivative of 4-aminomethyl2-nitrobenzoic acid (3) which was subsequently hydrolyzed with ammonia to give compound 4. Finally the fluorenylmethoxycarbonyl (Fmoc) derivative of 4aminomethyl-2-nitrobenzoic acid (5) was prepared. This compound is suitable for the incorporation of 2-nitrobenzyl groups in peptides using solid phase peptide protocols.

2. Synthesis and photolysis of peptides carrying photolabile linker. The peptide sequence TyrAla-7-PheLysGly (scheme 3) was prepared. Standard Fmoc-chemistry and solid-phase protocols were used. The desired peptide were purified by reverse-phase HPLC and characterized by mass spectrometry.

Aqueous solutions of the peptide sequence were irradiated with a Black Eye lamp (340 nm). The progress of the reaction was followed by HPLC-MS analysis of aliquots taken at different times. Photolysis of the peptide was nearly complete after 2 hours of irradiation (Figure 1). The $\mathrm{N}$-terminal fragment without the 2nitrosobenzaldehyde group was identified at the beginning of the chromatogram but the tripeptide carrying the 2-nitrosobenzaldehyde group was not observed. Instead several small peaks appeared along the chromatogram. It has been reported that the 2nitrosobenzaldehyde group may further react with amino groups [5, 14]. This side reaction prevent the isolation of the moiety carrying the 2-nitrosobenzaldehyde group.

3. Synthesis and photolysis of a model oligodeoxynucleotide carrying a photolabile linker. Next, an oligodeoxynucleotide carrying a photolabile group midsequence was prepared. Oligodeoxynucleotide sequence A, 5'-d(CCCCC-7-TTTT), was 
prepared on a $1 \mu \mathrm{mol}$ scale. The phosphoramidite $\mathbf{6}$ shown in Scheme 4 was used to introduce the photolabile 2-nitrobenzyl group at the midpoint of the sequence. This phosphoramidite has a methyl group at the benzyl position, which increases the reaction rate and prevents side reactions, as the methyl ketone group resulting from photolysis is less reactive than the aldehyde group. This compound (6) was obtained from commercial sources. After ammonia deprotection, the resulting oligodeoxynucleotide was purified by reverse-phase HPLC. Oligodeoxynucleotide A eluted at $10.2 \mathrm{~min}$ (Figure 2) as a broad double peak. The double peak was attributed to the presence of two diastereoisomers on the phosphoramidite used. The purified compound was characterized by mass spectrometry (MALDI). In addition to the expected mass, we observed two peaks corresponding to the fragmentation of the oligodeoxynucleotide $\left(\mathrm{T}_{4}\right.$ and $\mathrm{C}_{5}$-photolabile) that occurred during the acquisition of the spectra.

Oligodeoxynucleotide A was photolyzed with a Black Eye lamp (340 nm) for 30 minutes at room temperature. Figure 2 shows the HPLC profile of samples taken at the start of the photolysis and after 30 minutes of photolysis. Photolysis was almost completed after 30 minutes, as judged by the disappearance of the starting oligodeoxynucleotide. As the peak corresponding to sequence A disappeared, a new peak at 9 min was observed, which was identified as $\mathrm{T}_{4}$ by HPLC analysis of the enzyme digestion, giving thymidine as a single compound. The product containing 5 cytosines and the 2-nitrosophenylketone group was not isolated. We speculate that the moiety $\mathrm{C}_{5}$-photolabile undergoes further reactions, yielding several compounds. The presence of the methyl group at the benzyl position accelerated the photolysis but it did not prevent the formation of side products in the fragment carrying the 2nitrosophenylketone group. 
4. Synthesis and photolysis of an oligodeoxynucleotide hairpin carrying a photolabile linker at the apex of the loop.

Hairpin oligodeoxynucleotide sequence $\quad$ B, 5'-d(CTCAATGACTCGTT-8TTCGAGTCATTGAGTCATTTTT)-3', was prepared. The oligonucleotide has a selfcomplementary sequence of 15 base pairs linked by a tetrathymidine loop. In the middle of the loop there is the photolabile 2-nitrobenzyl group (8). This hairpin was designed to be immobilized to $\mathrm{SiO}_{2}$ surfaces in forthcoming experiments. For this reason, there are 5 thymidines at the 3'-end that will be used as a spacer to separate the hairpin from the surface.

After the assembly of the sequence and ammonia deprotection, the resulting oligonucleotide with the dimetoxytrityl (DMT) group was purified by reverse-phase HPLC and characterized by mass spectrometry. During HPLC purification a minor peak (20\% of the desired product) was observed corresponding to an extra oligonucleotide sequence with the DMT group. Mass spectrometry showed that the minor DMToligonucleotide sequence was a hydrolysis product of the desired compound near the photolabile site (scheme 4). This indicates that the photolabile linker is not totally stable under ammonia deprotection conditions but the desired full-length compound is easily separated from the hydrolysis compound. Photolysis was performed as described for the short oligonucleotide sequence, giving similar results (Figure 3). Most of the starting material disappeared after 30 min. This time a small peak was observed after the starting hairpin that was assigned to the 5'-fragment with the rest of the photolabile group. Denaturing gel electrophoresis confirmed the fragmentation of the hairpin and the formation of two bands of 14 and 24 bases.

Melting curves of the hairpin oligodeoxynucleotide (sequence B) with and without the presence of its complementary sequence (sequence C) were performed before and after 
photolysis. The hairpin shows a single duplex-to-random-coil transition with a melting temperature at $75^{\circ} \mathrm{C}$ (Figure 4A). The transition at $75^{\circ} \mathrm{C}$ was also the major transition of the hairpin in the presence of an equimolar amount of its complementary sequence (Figure 4B).

After 30 min of photolysis the melting curve was repeated. This time the transition was observed at a lower melting temperature $\left(T_{m}=50{ }^{\circ} \mathrm{C}\right.$, Figures $4 \mathrm{~A}$ and $\left.4 \mathrm{~B}\right)$, indicating that the intramolecular duplex was more stable than the intermolecular duplex. We are now examining the use of this difference in stability to fabricate patterns on surfaces. To this end we plan to immobilize oligodeoxynucleotide hairpins carrying photolabile groups on surfaces and create patterns of double-stranded and single-stranded DNA sequences by photolysis. Hybridization with complementary oligodeoxynucleotide conjugates is expected to allow the selective deposition of nanomaterials in the areas of single-stranded DNA resulting from the photolysis.

\section{Conclusions.}

We have demonstrated that photolabile 2-nitrobenzyl groups can be introduced into the middle of peptide and oligodeoxynucleotide derivatives, obtaining stable derivatives that can be purified and characterized using standard solid-phase synthesis protocols. Photocleavage of these compounds in aqueous solutions is achieved in minutes or in hours depending on the presence or absence of a methyl group in the benzylic position. After photolysis the moiety of the molecule carrying the resulting nitroso derivative is not easily found, probably due to further reactions of the resulting nitroso derivative [5, 14]. In contrast, the moiety of the molecule without the nitroso derivative is clearly observed and identified. 
An oligodeoxynucleotide hairpin carrying a photolabile group in the loop has been prepared. The modified hairpin has a very stable double-stranded form, as demonstrated by melting experiments. In the presence of the complementary strand, the modified hairpin maintains the entropy-favoured intramolecular form, as judged by the analysis of the melting curve. Photolysis of the hairpin generates two single-stranded molecules that have a lower melting temperature than the hairpin.

These results set the fundamental basis for the use of photolabile DNA hairpins in the manufacture of patterned surfaces by photolithography. Further work in this direction is in progress.

Acknowledgement. We thank Drs. Sónia Varón and Miriam Royo from the Combinatorial Chemistry Unit at PCB for their help in the HPLC-MS experiments. This study was supported by the Institute for Research in Biomedicine (IRB Barcelona), the Spanish Ministry of Education (BFU2007-63287), Generalitat de Catalunya (2005/SGR/00693), the Instituto de Salud Carlos III (CIBER-BNN, CB06_01_0019) and the European Community (NANO-3D NMP4-CT2005-014006).

\section{Experimental Part}

General. Phosphoramidites and ancillary reagents used during oligodeoxynucleotide synthesis were from Applied Biosystems (PE Biosystems Hispania S.A., Spain). The photolabile phosphoramidite 6 was from Link Technologies (Link Technologies Ltd, Scotland). The Fmoc-amino acids were from Novabiochem (Novabiochem GmbH, Switzerland). The rest of the chemicals were purchased from Aldrich, Sigma or Fluka (Sigma-Aldrich Química S.A., Spain). 
$N^{4}$-Trifluoroacetyl-4-aminomethylbenzoic acid (2). 4-Aminomethyl-benzoic acid 1 (3 g, 20mmol) was reacted with ethyl trifluoroacetate $(4.2 \mathrm{ml})$ in $20 \mathrm{ml}$ of ethanol containing $4.2 \mathrm{ml}$ of triethylamine at room temperature overnight [13]. The reaction mixture was concentrated to dryness and the resulting residue was dissolved in hot water (70 mL). The product precipitated on cooling and a few drops of trifluoroacetic acid were added, which induced more abundant precipitation. The desired product was isolated by filtration, which yielded $4.37 \mathrm{~g}$ (18 mmol, 90\%) of a white solid. Physical and spectroscopic properties as described elsewhere $[12,13]$.

$N^{4}$-Trifluoroacetyl-4-aminomethyl-2-nitrobenzoic acid (3). $\quad N^{4}$-Trifluoroacetyl-4aminomethyl benzoic acid 2 (18 mmol) was dissolved in $60 \mathrm{ml}$ of $95 \%$ concentrated sulfuric acid and the solution was cooled on ice. To the cooled solution a mixture of concentrated sulfuric acid $(2 \mathrm{ml})$ and $68 \%$ nitric acid $(1.6 \mathrm{ml})$ was added dropwise. After the addition the mixture was allowed to warm to room temperature. The resulting mixture was poured over to $500 \mathrm{~g}$ of crushed ice. The resulting precipitate was filtered off yielding $5.3 \mathrm{~g}(18 \mathrm{mmol})$ of a solid that was used without further purification. Physical and spectroscopic properties as described elsewhere [12, 13].

$N^{4}$-(9-Fluorenylmethoxy)carbonyl-4-aminomethyl-2-nitrobenzoic acid (5).

$\mathrm{N}^{4}$-Trifluoroacetyl-4-aminomethyl-2-nitrobenzoic acid $3(0.2 \mathrm{~g}, 0.68 \mathrm{mmol})$ was dissolved in a 1:1 mixture of dioxane and 30\% aqueous ammonia (10 $\mathrm{ml})$ and the resulting solution was stirred overnight at room temperature. The resulting solution was concentrated to dryness, yielding a brown residue (4) that was used without further purification. 
The residue was dissolved in a 1:1 mixture of dioxane and $10 \% \mathrm{Na}_{2} \mathrm{CO}_{3}$ aqueous solution $(20 \mathrm{ml})$. The resulting mixture was cooled in an ice bath and $100 \mathrm{mg}$ of fluorenylmethyloxycarbonate N-hydroxysuccinimyl ester (Fmoc-OSu) dissolved in 10 $\mathrm{ml}$ of dioxane was added. The mixture was stirred at $4^{\circ} \mathrm{C}$ for $45 \mathrm{~min}$ and allowed to warm to room temperature. After 1 hour of magnetic stirring $30 \mathrm{ml}$ of water was added and the mixture was treated with $20 \mathrm{ml}$ of ethyl ether (3 times). The aqueous layer was concentrated to half of its volume and the resulting solution was cooled in an ice bath. The cooled solution was acidified to $\mathrm{pH} 2$ with $32 \% \mathrm{HCl}$ aqueous solution. A white precipitate is formed that was collected by filtration, yielding $184 \mathrm{mg}(0.44 \mathrm{mmol}, 65 \%)$ of a white solid. Physical and spectroscopic properties as described elsewhere [12].

Peptide Synthesis. The peptide sequence $\mathrm{H}^{-}{ }^{\mathrm{N}}$ Tyr-Ala-7-Phe-Lys-Gly ${ }^{\mathrm{C}}-\mathrm{OH}$ was prepared using solid phase methodology and Fmoc-amino acids. Tyrosine was protected with the tert-butyl group and lysine with the tert-butoxycarbonyl group. The peptide was assembled on polystyrene support functionalized with Fmoc-Gly from commercial sources (Fmoc-Gly-Wang-polystyrene [15], $0.51 \mathrm{mmol} / \mathrm{g}, 50 \mathrm{mg}, 25 \mu \mathrm{mol}$ ). The peptide chain was elongated in $0.5 \mathrm{ml}$ DMF using 5-fold excess of the Fmoc-amino acid and 5fold excess of benzotriazol-1-yl- $N$-oxy-tris(pyrrolidino)phosphonium hexafluorophosphate (PyBOP) and 10 fold excess of $N, N$-diisopropylethyl amine for $1 \mathrm{~h}$. After the assembly of the sequences, the support was treated with $2 \mathrm{ml}$ of trifluoroacetic acid / water (95:5) solution for 3 h. The support was removed by filtration and the resulting solution was treated with $50 \mathrm{ml}$ of ethyl ether. A white precipitate was isolated by filtration. The resulting product was purified by reverse-phase HPLC and the desired product was obtained as the major component $(\mathrm{M}=763.4$; expected 762.9). 
Oligodeoxynucleotide synthesis. Oligodeoxynucleotides sequences A: 5'-d(CCCCC-8TTTT)-3’， B: 5’-d(CTCAATGACTCGTT-8-TTCGAGTCATTGAGTCATTTTT)-3’, and C: 5'-d(TGACTCAATGACTCG)-3' were prepared using solid-phase methodology and 2-cyanoethyl phosphoramidites as monomers. The photolabile phosphoramidite (PC spacer-CE phosphoramidite, Link Technologies) was used to introduce the photolabile function. The syntheses were performed on an Applied Biosystems Model 3400 DNA synthesizer. After the assembly of sequences, ammonia deprotection was performed either for $2 \mathrm{hr}$ at room temperature (sequence A) or overnight at $55{ }^{\circ} \mathrm{C}$ (sequence B). Oligonucleotides were purified by reverse-phase HPLC. HPLC solutions were as follows. Solvent A: 5\% acetonitrile in $100 \mathrm{mM}$ triethylammonium acetate (pH 6.5) and solvent B: $70 \%$ acetonitrile in $100 \mathrm{mM}$ triethylammonium acetate $\mathrm{pH}$ 6.5. Columns: Nucleosil 120C18 $(10 \mu \mathrm{m}), 200$ x $10 \mathrm{~mm}$. Flow rate: $3 \mathrm{ml} / \mathrm{min}$. Conditions A (DMT on): 20 min linear gradient from 15-80\% B. Conditions B (DMT off): 20 min linear gradient from $0-50 \% \mathrm{~B}$.

MS: Sequence A (MALDI): Found $2942.8(\mathrm{M}-\mathrm{H})$; expected for $\mathrm{C}_{98} \mathrm{H}_{130} \mathrm{~N}_{25} \mathrm{O}_{63} \mathrm{P}_{9}$, 2943.5. In addition to the expected mass, we observed two peaks corresponding to the fragmentation of the oligodeoxynucleotide $\left(\mathrm{T}_{4}\right.$, found 1233.5 expected for $\mathrm{C}_{40} \mathrm{H}_{49} \mathrm{~N}_{8} \mathrm{O}_{29} \mathrm{P}_{4}, 1234.2$ and $\mathrm{C}_{5}$-photolabile group, found 1710.4 expected for $\mathrm{C}_{58} \mathrm{H}_{71} \mathrm{~N}_{17} \mathrm{O}_{34} \mathrm{P}_{5}, 1709.3$ ). Yield: 7 O.D. Units at $260 \mathrm{~nm}$.

MS: Sequence B (MALDI): Found $11336.7(\mathrm{M}-\mathrm{H})$; expected for $\mathrm{C}_{366} \mathrm{H}_{465} \mathrm{~N}_{120} \mathrm{O}_{230} \mathrm{P}_{36}$, 11339. In addition to the expected mass, we observed two peaks corresponding to the fragmentation of the oligodeoxynucleotide (3'-fragment, found 6804.7 expected for $\mathrm{C}_{217} \mathrm{H}_{277} \mathrm{~N}_{71} \mathrm{O}_{140} \mathrm{P}_{22}$, 6800.5 and 5'-fragment-photolabile group, found 4545.85 expected for $\left.\mathrm{C}_{149} \mathrm{H}_{189} \mathrm{~N}_{49} \mathrm{O}_{90} \mathrm{P}_{14}, 4539.5\right)$. Yield: 33 O.D. units at $260 \mathrm{~nm}$. 
In addition to the expected product a minor product corresponding to an oligodeoxynucleotide sequence with a DMT group was also observed. This was identified as the product of the hydrolysis or ammonolysis of the amide present in the photolabile compound $(\mathrm{M}=4385)$.

Photolysis of peptide and oligodeoxynucleotides. Aqueous solutions (2 ml) of peptide (0.9 mM) or oligodeoxynucleotide $(0.07 \mathrm{mM})$ were photolyzed with a Black Eye lamp (340 nm) at room temperature. Aliquotes of $0.2 \mathrm{ml}$ were taken at different time points (10, 30, 60, $120 \mathrm{~min}$ ) and analyzed by HPLC. The peptide solutions were analyzed by HPLC-MS. HPLC solutions were as follows. Solvent A: $0.1 \%$ formic acid in water and solvent B: $0.07 \%$ formic acid in acetonitrile. Columns: Spherisorb C18 $(5 \mu \mathrm{m}), 100 \times 5$ mm. Flow rate: $1 \mathrm{ml} / \mathrm{min}$. Conditions A: 10 min linear gradient from 0-50\% B. Figure 1 shows the HPLC profile of samples taken at the start and after 2 hours. The starting material (retention time $4.6 \mathrm{~min}, \mathrm{M}=763.4$ ) disappeared and the fragment TyrAla was found at retention time $2.4 \min \left(\mathrm{M}=272.1\left[\mathrm{M}+\mathrm{Na}^{+}-\mathrm{H}^{+}\right]\right.$, expected 251.2). The oligodeoxynucleotide solutions were analyzed by HPLC as described in the purification of oligodeoxynucleotides (conditions B). Figures 2 and 3 show the HPLC profile of samples taken at the start of the photolysis and after 30 minutes. In the photolysis of sequence $\mathrm{A}$, a new peak at 9 min was observed which was identified as $\mathrm{T}_{4}$ by HPLC analysis of the enzyme digestion of the product (snake venom phosphodiesterase and alkaline phosphatase [16]) that gave thymidine as single compound. The product containing 5 cytosines and the photolabile group was not isolated. In the photolysis of oligodeoxynucleotide sequence B a small peak was observed eluting after the hairpin, which was assigned to the fragment at the 5' with the rest of the photolabile groups. 
Denaturing gel electrophoresis confirmed the fragmentation of the hairpin and the formation of two bands of 14 and 24 bases.

Melting Studies. Oligodeoxynucleotide hairpin B with or without an equimolar amount of its complementary sequence (sequence C) was dissolved in an aqueous buffer containing $0.15 \mathrm{M} \mathrm{NaCl}, 1 \mathrm{mM} \mathrm{MgCl}_{2}$, and $10 \mathrm{mM}$ sodium phosphate $\mathrm{pH}=7.13$ and placed in a spectrophotometer equipped with temperature controller. Melting experiments were done in the temperature range from $15{ }^{\circ} \mathrm{C}$ to $80{ }^{\circ} \mathrm{C}$ with a linear temperature ramp of $0.5{ }^{\circ} \mathrm{C} / \mathrm{min}$. Absorbance spectra were recorded every $1{ }^{\circ} \mathrm{C}$. Each sample was allowed to equilibrate at the initial temperature for 30 minutes before the melting experiment was started.

HPLC analysis of the solution of the hairpin alone obtained after the melting experiment showed the presence of a $15 \%$ of the photolyzed hairpin. This partial photolytic cleavage is due to the UV light used during the melting experiment. A second melting experiment with the same sample showed a small transition at around $50{ }^{\circ} \mathrm{C}$ due to the presence of the photolyzed hairpin produced during the first melting experiment.

\section{REFERENCES}

[1] Y. V. Il’ichev, M. A. Schwörer, J. Wirz, J. Am. Chem. Soc. 2004, 126, 4581.

[2] C. G. Bochet, J. Chem. Soc. Perkin Trans. I 2002, 125.

[3] Y. V. Il’ichev, J. Phys. Chem. A 2003, 107, 10159.

[4] M. Gaplovsky, Y. V. Il'ichev, Y. Kamdzhilov, S. V. Kombarova, M. Mac, M. A. Schwörer, J. Wirz, Photochem. Photobiol. Sci. 2005, 4, 33.

[5] V. N. R. Pillai, Synthesis 1980, 1. 
[6] D. H. Rich, S. K. Gurwara, J. Am. Chem. Soc. 1973, 97, 1575.

[7] E. Giralt, F. Albericio, E. Pedroso, C. Granier, J. Van Rietschoten, Tetrahedron 1982, 38, 1193.

[8] D. H. Rich, S. K. Gurwara, Tetrahedron Lett. 1975, 16, 301.

[9] F. Albericio, M. Pons, E. Pedroso, E. Giralt, J. Org. Chem. 1989, 54, 360.

[10] G. Dormán, G. D. Prestwich, Trends Biotechnol., 2000, 18, 64.

[11] D. Kapranov, J. Drenkow, J. Cheng, J. Long, G. Helt, S. Dike, T. R. Gingeras, Genome Res. 2005, 15, 987.

[12] R. P. Hammer, F. Albericio, L. Gera, G. Barany, Int. J. Peptide Protein Res. 1990, 36, 31.

[13] T. V. Abramova, V. N. Silnikov, Nucleosides Nucleotides Nucleic Acids 2005, 24, 1333.

[14] A. Patchornik, B. Amit, R. B. Woodward, J. Am. Chem. Soc. 1970, 92, 6333.

[15] S. S. Wang, J. Am. Chem. Soc. 1973, 95, 1328.

[16] D. Fernández-Forner, Y. Palom, S. Ikuta, E. Pedroso, R. Eritja, Nucleic Acids Res. 1990, 18, 5729. 


\section{LEGENDS}

Scheme 1. Synthesis of a photolabile linker used for the introduction of 2-nitrobenzyl groups in peptides.

Scheme 2. Synthesis of the photolabile linker needed for the incorporation of 2nitrobenzyl bonds in peptides.

Scheme 3. Phosphoramidite derivative used for the incorporation of 2-nitrobenzyl bonds in oligonucleotides .

Scheme 4. Structure of photolabile linkers 7 and $\mathbf{8}$ and hydrolysis product found during the purification of the DMT-oligonucleotide hairpin .

Figure 1. Photolysis of peptide $\mathrm{H}^{\mathrm{N}}{ }^{\mathrm{T}}$ Tyr-Ala-7-Phe-Lys-Gly ${ }^{\mathrm{C}} \mathrm{-OH}$. HPLC profiles of samples taken at the start $(\mathrm{t}=0)$ and after 120 min of photolysis.

Figure 2. Photolysis of oligonucleotide 5'-CCCCC-8-TTTT-3'. HPLC profiles of samples taken at the start $(\mathrm{t}=0)$ and after 30 min of photolysis.

Figure 3. Photolysis of oligonucleotide hairpin B. HPLC profiles of samples taken at the start $(\mathrm{t}=0)$ and after 30 min of photolysis.

Figure 4. Melting curves of oligonucleotide hairpin B. A) Hairpin alone before and after photolysis; B) Hairpin in the presence of complementary oligodeoxynucleotide (sequence C) before and after photolysis. Conditions: $0.15 \mathrm{M} \mathrm{NaCl}, 1 \mathrm{mM} \mathrm{MgCl}$, and 10 mM sodium phosphate $\mathrm{pH}=7.13$. 
Scheme 1.

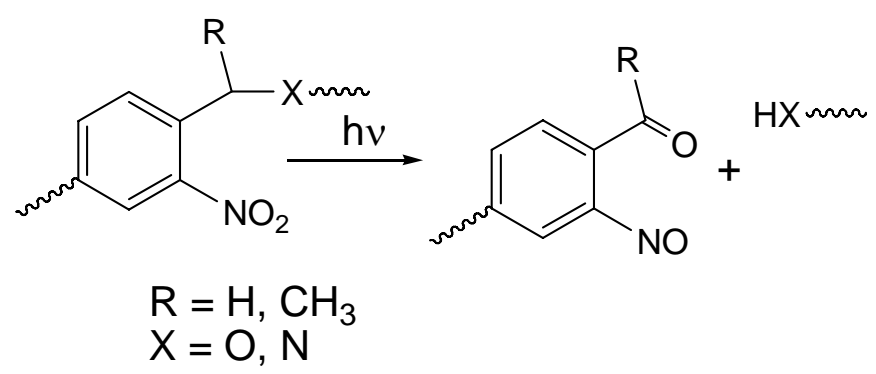

Reduce to $70 \%$ of current size for publication

Scheme 2

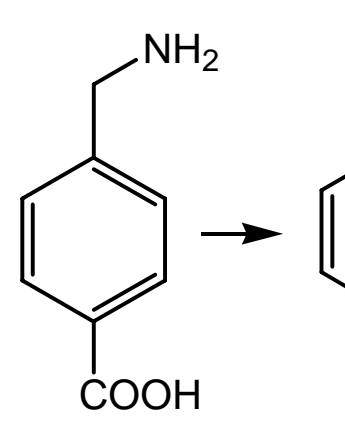<smiles>O=C(O)c1ccc(CNC(=O)C(F)(F)F)cc1</smiles><smiles>O=C(O)c1ccc(CNC(=O)C(F)(F)F)c([N+](=O)[O-])c1</smiles><smiles>NCc1ccc(C(=O)O)cc1[N+](=O)[O-]</smiles>

4

5 
Scheme 3

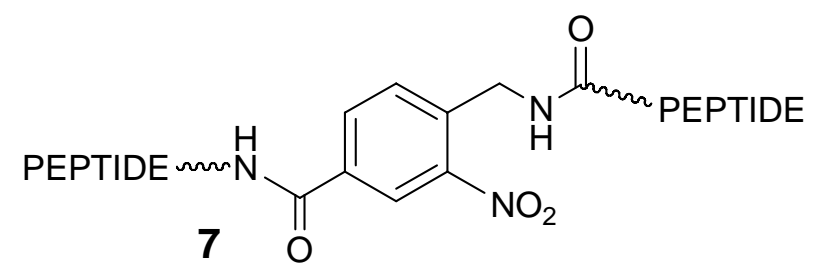

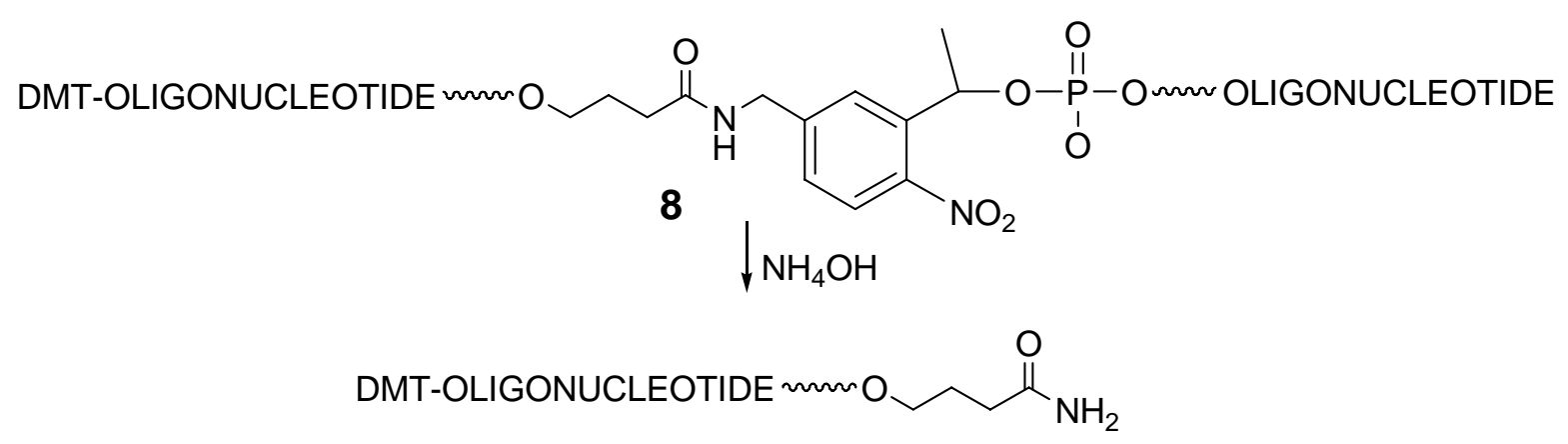
REDUCE TO 70\% OF CURRENT SIZE FOR PUBLICATION

Scheme 4<smiles></smiles>

REDUCE TO 70\% OF CURRENT SIZE FOR PUBLICATION 
Figure 1.

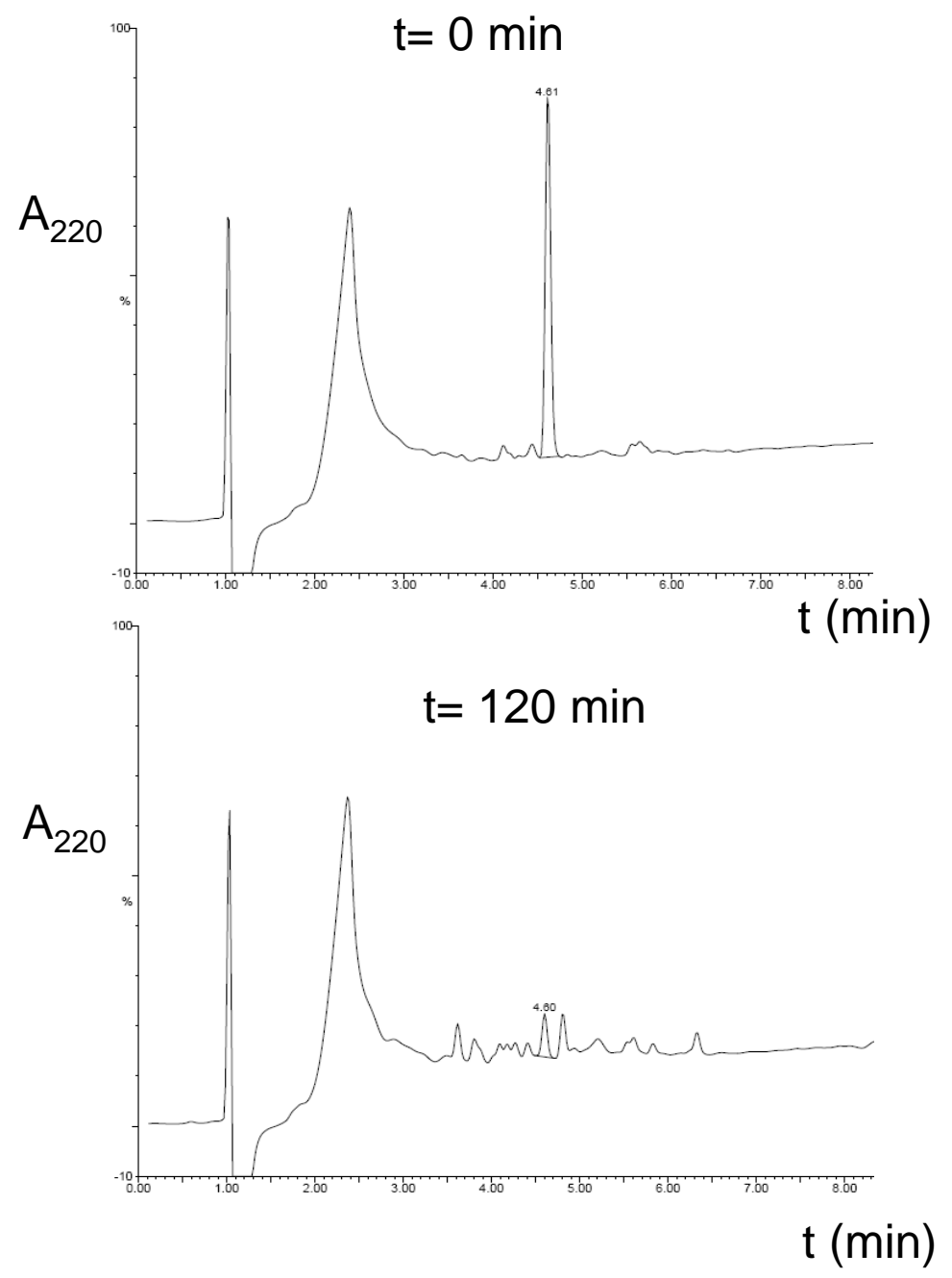


Figure 2.
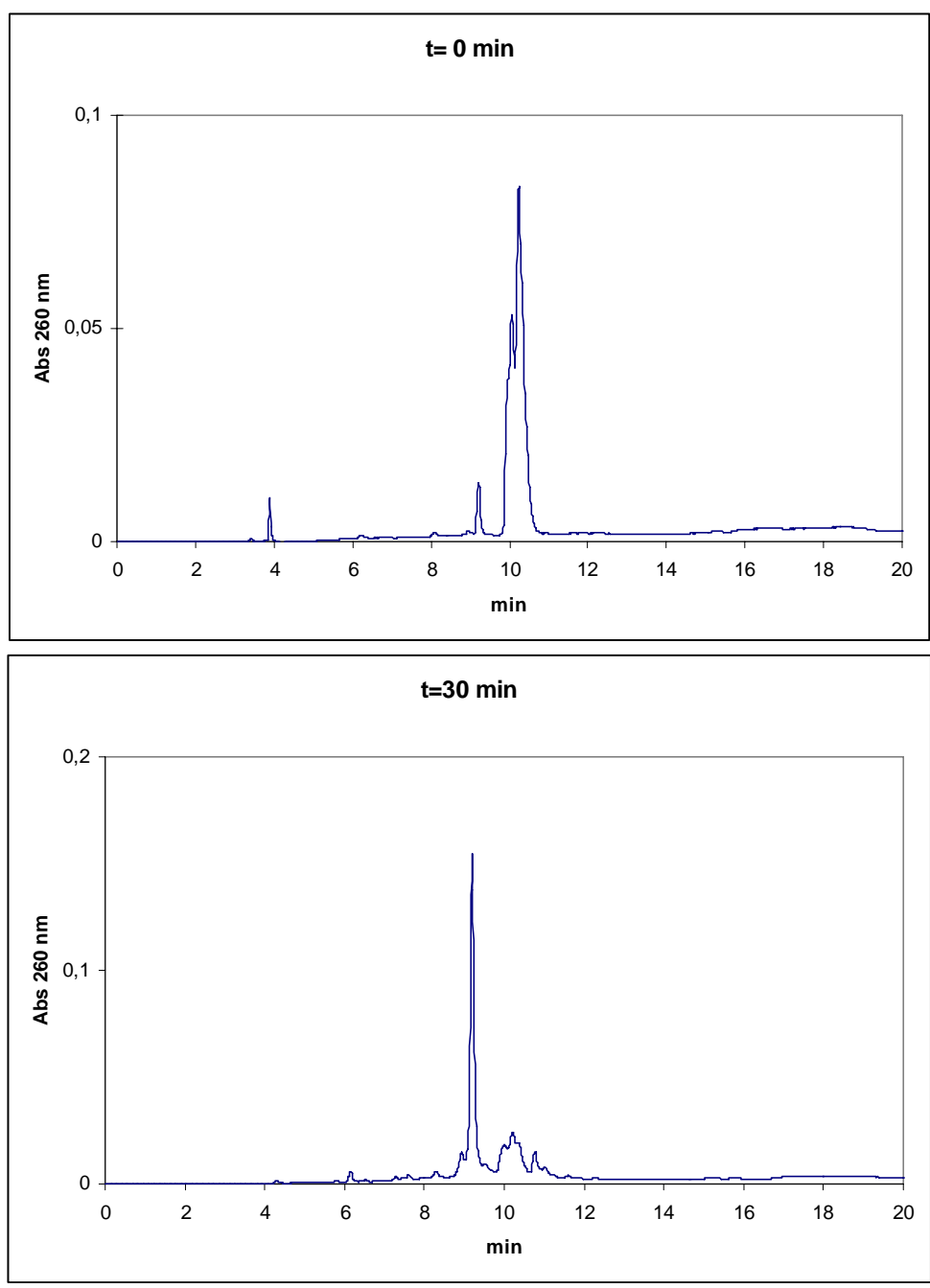
Figure 3
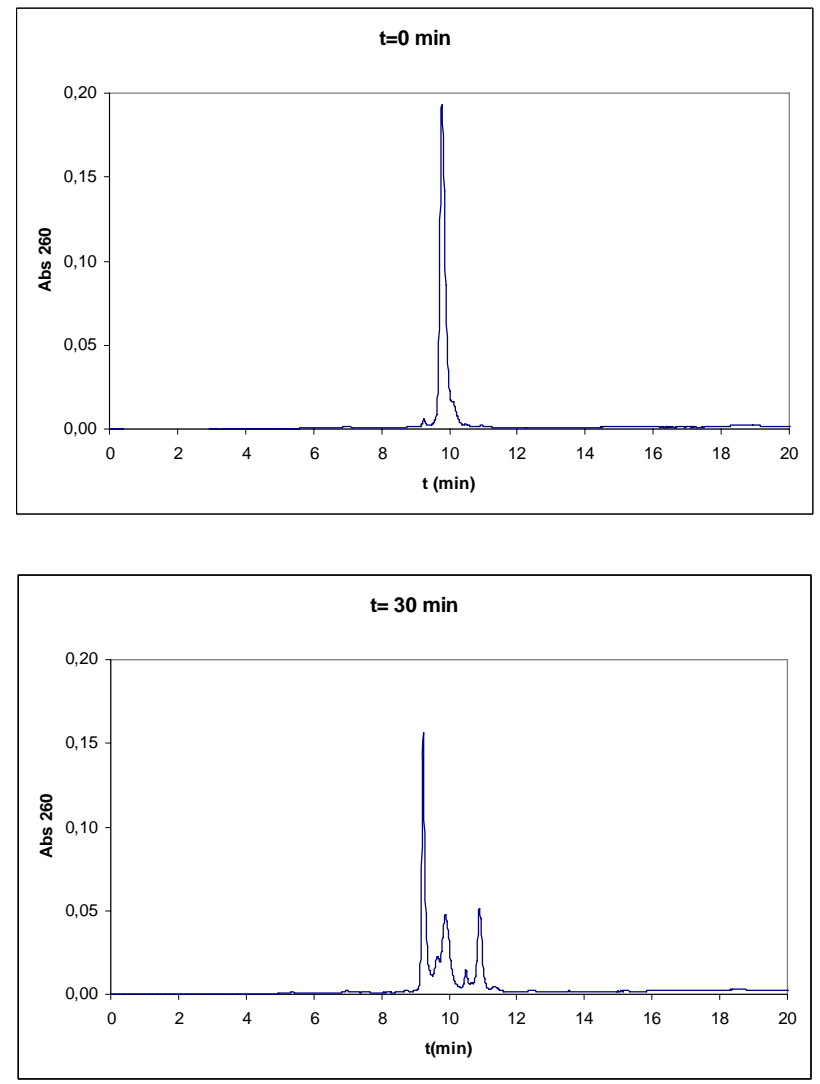
Figure 4A

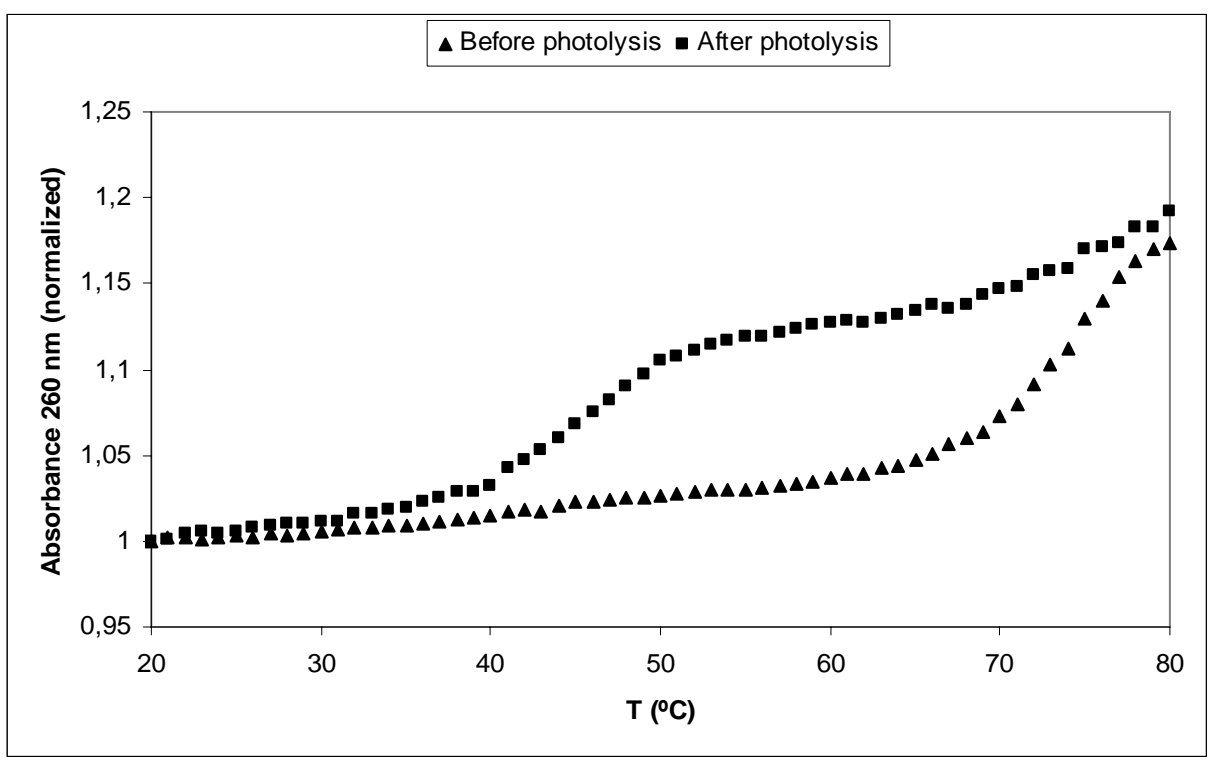

Figure 4B

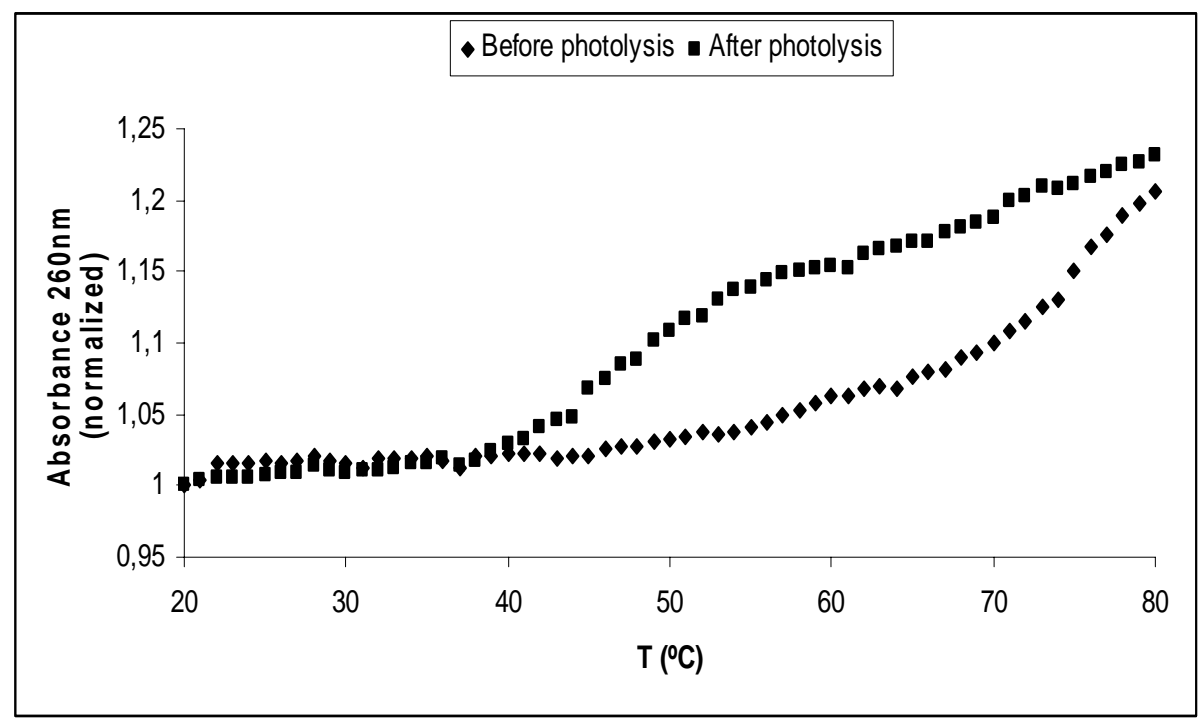


Graphical illustration for the table of contents
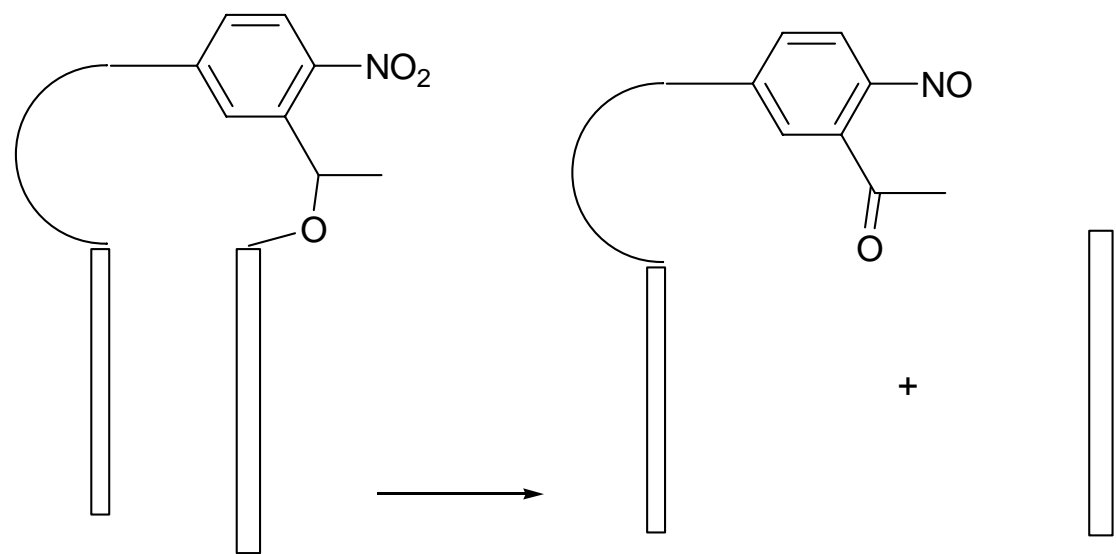

REDUCE TO 70\% OF CURRENT SIZE FOR PUBLICATION 